\title{
Charge Transport in Metal-Oxide Interfaces: Genesis and Detection of Hot Electron Flow and Its Role in Heterogeneous Catalysis
}

\author{
Sun Mi Kim $\cdot$ Hyosun Lee $\cdot$ Jeong Young Park
}

Received: 13 October 2014/ Accepted: 29 October 2014/Published online: 8 November 2014

(c) Springer Science+Business Media New York 2014

\begin{abstract}
Most nanocatalysts are composed of highly dispersed transition metal nanoparticles on oxides. The interface between the metal nanoparticles and the oxides plays a crucial role in determining the catalytic performance of the nanocatalysts. Due to non-adiabatic electronic excitation, energetic electrons in metals can be generated during exothermic chemical processes. The energy barrier formed at the metal-oxide interfaces leads to the irreversible transport of energetic, or hot, electrons. The dopants and impurities present on the oxides can generate additional charge carriers or oxygen vacancies that affect the catalytic activity. The accumulation or depletion of hot electrons on the metal nanoparticles, in turn, can also influence the catalytic reactions. In this article, we outline recent studies of the role of metal oxide interfaces and characteristics of fast charge transfer between metals and oxides. The electronic configuration of metal-oxide nanocatalysts during catalytic reactions will be introduced and its influence on heterogeneous catalysis will be outlined.
\end{abstract}

Keywords Hot electron - Metal-oxide interface · Dopants · Oxygen vacancy $\cdot$ Heterogeneous catalysis

S. M. Kim $\cdot$ H. Lee $\cdot$ J. Y. Park $(\bowtie)$

Center for Nanomaterials and Chemical Reactions, Institute for Basic Science, Daejeon 305-701, Republic of Korea

e-mail: jeongypark@kaist.ac.kr

S. M. Kim · H. Lee $\cdot$ J. Y. Park

Graduate School of EEWS, KAIST, Daejeon 305-701, Republic

of Korea

\section{Introduction}

Industrial catalysts are mainly composed of metal particles in the 1-100 nm size regime dispersed in a high-surfacearea support. They are produced by synthesizing the metal particles and support separately and then dispersing the metal clusters onto the support using various techniques (e.g., wet-impregnation, co-precipitation, or ion-exchange). The discontinuity between well-characterized model systems and industrially relevant catalysts represent the materials gap that has been a long-standing issue in heterogeneous catalysis [1-3].

One of the key issues in 'bridging materials gaps' is elucidating the role of metal-oxide interfaces in altering catalytic activity. The smart design of nanocatalysts can improve the catalytic activity of transition metals on reducible oxide supports. Figure 1a, b shows a scheme of the electronic configuration and the energy band diagram for metal-oxide interfaces under catalytic reactions. Electron excitation in exothermic catalytic reactions or the incidence of photons on metal surfaces results in the flow of high-energy electrons with an energy of $1-3 \mathrm{eV}$, assuming that most of the chemical or photon energy is converted to electron flow on a short (femtosecond) time scale before atomic vibration adiabatically dissipates the energy (picoseconds). The energetic electrons that are not in thermal equilibrium with the metal atoms are called "hot electrons". The Schottky barrier localized at the metaloxide interface allows hot electrons to irreversibly transport through the interface.

There are a number of studies that indicate the significance of the metal-oxide interface. Earlier studies of $\mathrm{Au} /$ $\mathrm{TiO}_{2}$ suggest that the perimeter area between the $\mathrm{Au}$ nanoparticles and $\mathrm{TiO}_{2}$ is catalytically reactive under $\mathrm{CO}$ oxidation [4,5]. This effect was also investigated by Boffa 
Fig. 1 a Electronic

configuration and $\mathbf{b}$ energy band

diagram of metal-oxide

catalysts under chemical reactions illustrating (1) the

flow of fast and energetic charge

carriers, (2) formation of a

Schottky barrier, (3) effect of dopants and oxygen vacancies, and (4) manipulation of hot carriers generated by photon absorption (a)

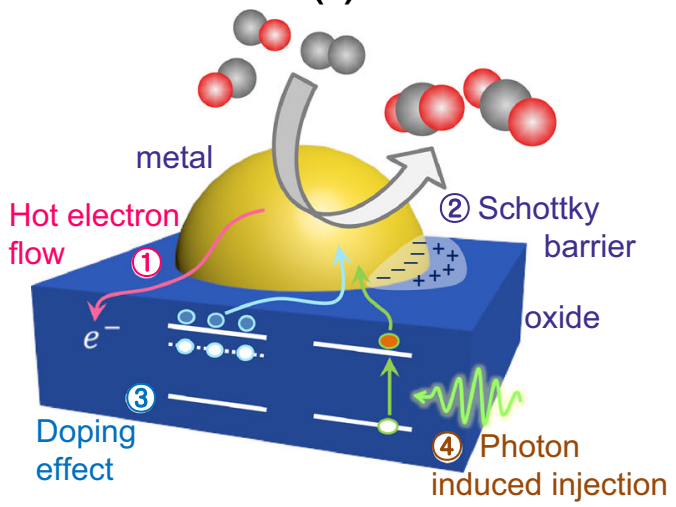

(b)

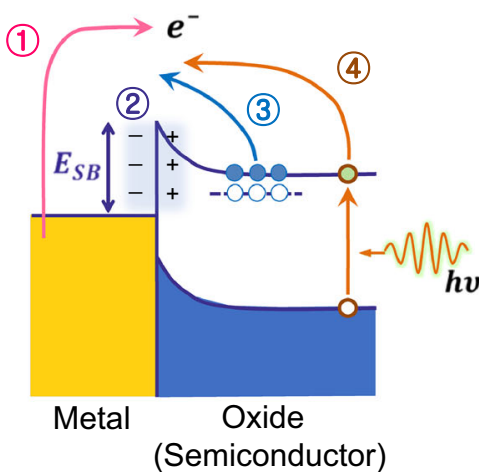

et al. [6] using rhodium deposited on a large assortment of oxides. They observed a remarkable 14-fold increase in turnover rates for $\mathrm{CO}_{2}$ hydrogenation, especially in the presence of three different oxides: $\mathrm{TiO}_{\mathrm{x}}, \mathrm{NbO}_{\mathrm{x}}$, and $\mathrm{TaO}_{\mathrm{x}}$. The activity was highest when the oxide-metal interface area was at a maximum, which occurred at $\sim 0.5$ monolayer of oxide coverage. On the other hand, several other oxides, including $\mathrm{ZrO}_{\mathrm{x}}, \mathrm{VO}_{\mathrm{x}}, \mathrm{WO}_{\mathrm{x}}$, and $\mathrm{FeO}_{\mathrm{x}}$, exhibit minor effects of coverage dependence. Interestingly, three oxides (i.e., $\mathrm{TiO}_{\mathrm{x}}, \mathrm{NbO}_{\mathrm{x}}$, and $\mathrm{TaO}_{\mathrm{x}}$ ) have bandgaps between 3.3 and $4.4 \mathrm{eV}$, which leads to the formation of a Schottky barrier between the oxides and the Rh film. These results indicate that the bandgap, or the presence of a Schottky barrier, plays a crucial role in determining the catalytic activity. Similar results on the effect of oxides on the catalytic activity of $\mathrm{CO}$ oxidation were also reported by Park et al. [7]. Doping or impurities in the oxides can result in excess charge carriers or oxygen vacancies on the oxides that lead to a change in catalytic activity [8,9]. Additionally, charge accumulation or the depletion of hot electrons generated by photon absorption can be utilized to control catalytic activity, as illustrated in Fig. 1.

In this paper, we show the influence of metal-oxide interfaces on heterogeneous catalysis, focusing on the impact of electronic properties, including doping, bandgap, and Schottky barriers. We will outline the aspects of fast charge transfer between metal nanoparticles and oxides (semiconductors) that were uncovered using spectroscopic techniques with temporal resolution of femtoseconds. The correlation between the hot electron flows and catalytic activity under various exothermic reactions will be addressed.

\section{Significance of Charge Transfer at Metal-Oxide Interfaces in Catalysis}

When metal catalysts are mixed with semiconductor support materials, the composites show integrated and unprecedented properties that arise at the heterostructure interface. Enhancement of the catalytic activity on mixed catalysts was first investigated by Schwab $[10,11]$ and Solymosi [12]. These phenomena have been referred to as the "strong metal-support interaction" (SMSI), which was commonly used to describe the promoting and prohibiting effects of the support on the catalytic activity of the metal that cannot be explained as purely structural. Studies of the SMSI effect have increased in parallel with the advancement of diverse catalyst synthesis techniques and a variety of support materials that are improving the performance of supported catalysts. In particular, enormous efforts have been devoted to gaining a thorough understanding of the nature of the SMSI effect [13-16]. The general conclusion is that the interactions of the metal supports are influenced by three key properties: energetics of the metal particles (i.e., the properties reflecting the cohesive energy of a particle), geometric properties (e.g., those describing shape, size, crystal phase, order, strain, and structure), and electronic properties (e.g., those describing band structure, electron binding energies, and interactions of electrons with magnetic fields).

Among the various origins mentioned above, the predominant agreement is that the SMSI effect is ascribed to the alternation of the electronic structure of the metal by charge transfer to or from a support. Since metals normally have a smaller work function $\left(\Phi_{\mathrm{m}}\right)$ than semiconductors, the energy bands $\left(E_{C}\right.$ and $E_{V}$ ) of the semiconductor are bent downwards when the two phases are in electric contact, as shown in Fig. 2a. Schwab's earlier results on mixed catalysts reveal a surprisingly superior action of the $\mathrm{Ag} / \mathrm{ZnO}$ catalyst where silver $(\mathrm{Ag})$ is combined with zinc oxide $(\mathrm{ZnO})$. It is clear that for methanol oxidation, the mixed $\mathrm{Ag} / \mathrm{ZnO}$ catalyst gives an extremely high yield of carbon dioxide $\left(\mathrm{CO}_{2}\right)$ and water vapor $\left(\mathrm{H}_{2} \mathrm{O}\right)$ even at lower temperatures, in contrast with the individual catalysts (Ag and $\mathrm{ZnO}$ ), as shown in Fig. 2b. This result can be explained by electron transfer from the metal into the semiconductor. Electrons have diffused from the metal into the 
(a)

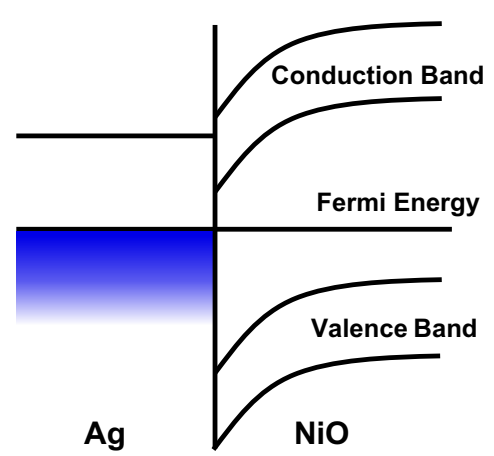

(b)

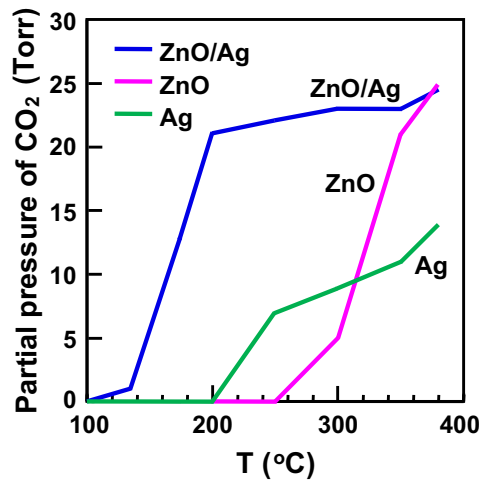

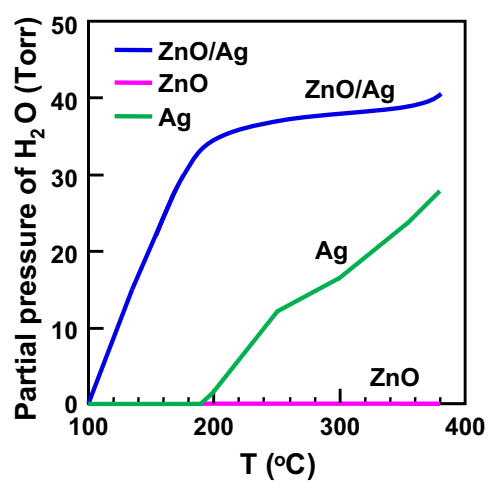

Fig. 2 a Band model of the inverse mixed metal-semiconductor catalyst, $\mathrm{Ag} / \mathrm{NiO}$, and $\mathbf{b}$ combined actions of the mixed metalsemiconductor $\mathrm{Ag} / \mathrm{ZnO}$ catalysts: partial pressure of carbon dioxide
$\left(\mathrm{CO}_{2}\right.$, left $)$ and water vapor $\left(\mathrm{H}_{2} \mathrm{O}\right.$, right $)$ as a function of temperature. Reprinted from Ref. [10]. Copyright 2014, with permission from the American Chemical Society
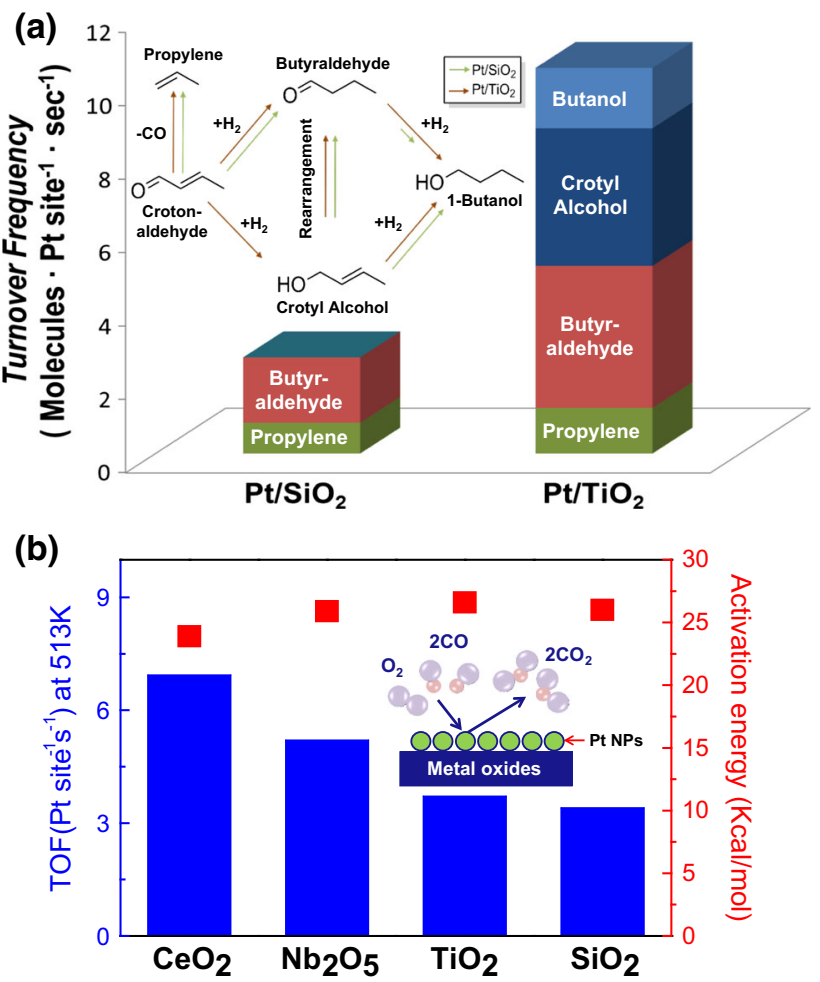

Fig. 3 a Turnover frequencies (TOFs) for the four observed products are reported for both the $\mathrm{Pt} / \mathrm{SiO}_{2}$ and $\mathrm{Pt} / \mathrm{TiO}_{2}$ catalysts. Similar rates of propylene production are observed for both catalysts. Butanol and crotyl alcohol production is only observed on the $\mathrm{Pt} / \mathrm{TiO}_{2}$ catalysts. (Inset Reaction scheme showing all the product pathways observed in the course of the reaction studies. Two sets of arrows represent the activity for each pathway for $\mathrm{Pt} / \mathrm{SiO}_{2}$ and $\mathrm{Pt} / \mathrm{TiO}_{2}$ ). b Summary of the TOFs at $513 \mathrm{~K}$ and activation energies for the $\mathrm{CO}$ oxidation reaction measured on colloidal $4.1 \mathrm{~nm}$ Pt nanoparticles. Reprinted from Ref. [7, 18]. Copyright 2014, with permission from Wiley-VCH Verlag $\mathrm{GmbH} \& \mathrm{Co}$ KGaA, Weinheim [18] and Elsevier [7]

role in activating oxygen to react with the chemisorbed $\mathrm{CO}$ at the interface, controlling the activity of the $\mathrm{Pt}$ nanoparticles. 
(a)

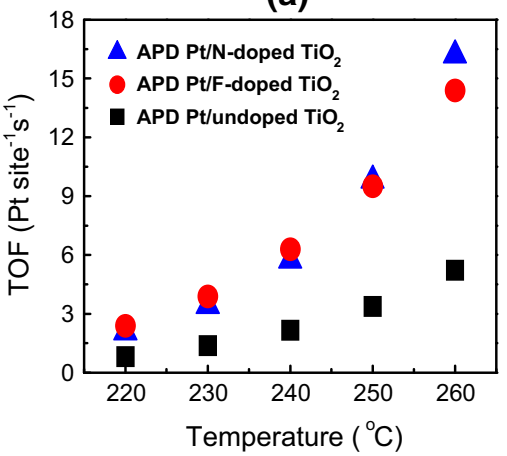

Fig. 4 Catalytic activity of $\mathrm{CO}$ oxidation results: a turnover frequencies (TOFs) of Pt nanoparticles on F-doped $\mathrm{TiO}_{2}, \mathrm{~N}$-doped $\mathrm{TiO}_{2}$, and undoped $\mathrm{TiO}_{2}$. b Schematic diagram of the dissociation of $\mathrm{O}_{2}$ by oxygen vacancies and the corresponding $\mathrm{CO}$ oxidation reaction on $\mathrm{Pt} /$ $\mathrm{N}$-doped $\mathrm{TiO}_{2}$ catalysts. c Schematic diagram of the proposed

Doping of the oxide is another way to tune the electronic states of the oxide supports and influences the chemical reaction process, resulting in changes in the catalytic activity and activation energy of catalysts [9]. Figure 4 shows the turnover rates of $\mathrm{Pt}$ nanoparticles on F-doped $\mathrm{TiO}_{2}$, N-doped $\mathrm{TiO}_{2}$, and undoped $\mathrm{TiO}_{2}$ and the proposed mechanism to explain these $\mathrm{CO}$ oxidation results. As shown in Fig. $4 \mathrm{a}$, the activities of the $\mathrm{Pt}$ nanoparticles supported on $\mathrm{F}$ - or $\mathrm{N}$-doped $\mathrm{TiO}_{2}$ are a factor of $\sim 2.5$ higher than that of $\mathrm{Pt}$ nanoparticles on undoped $\mathrm{TiO}_{2}$. These results indicate that the insertion of dopants changes the electronic states of the $\mathrm{TiO}_{2}$ support, and that it drives the $\mathrm{CO}$ oxidation reaction. The proposed mechanisms for the enhancement of catalytic activity on $\mathrm{N}$-doped and F-doped $\mathrm{TiO}_{2}$ are shown in Fig. $4 \mathrm{~b}$, c, respectively. When nitrogen is doped into $\mathrm{TiO}_{2}$, the oxygen vacancies are formed on the surface of the $\mathrm{TiO}_{2}$ and it contributes to the dissociation of oxygen molecules and activation of the $\mathrm{CO}$ oxidation reaction (Fig. 4b). In the case of $\mathrm{Pt} / \mathrm{F}$-doped $\mathrm{TiO}_{2}$, electron transfer from the conduction band of $\mathrm{TiO}_{2}$ to the adsorbed oxygen forms an activated $\mathrm{O}^{-}$intermediate that easily reacts with $\mathrm{CO}$ (Fig. 4c).

\section{Detection of Fast Charge Transfer in the Temporal Regime on Metal-Oxide Interfaces}

Gaining insight into the general dynamics of photoexcited charge carriers at metal-oxide interfaces is a fundamental step to study the role of metal-oxide interfaces and hot electron flows in heterogeneous catalysis. In this context, the spectroscopic investigation of various hybrid nanocomposites using ultrashort (picosecond and femtosecond) laser pulses in different wavelength regions (visible, infrared, UV, and X-ray) has been carried out [19-23]. Since ultrafast spectroscopy involves temporally short, electronic activation mechanism of surface oxygen by charge transfer from the conduction band of $\mathrm{TiO}_{2}$ to the adsorbed $\mathrm{O}$ on $\mathrm{Pt} / \mathrm{F}$-doped $\mathrm{TiO}_{2}$ catalysts. Reprinted from Ref. [9]. Copyright 2014, with permission from Springer

therefore spectrally broad light pulses, this technique is useful to directly probe the dynamics of the system rather than the energy levels themselves. Mongin et al. investigated ultrafast charge separation in a model system of goldtipped CdS nanorods with a matchstick architecture using the optical time-resolved pump-probe technique. Electronhole pairs photoexcited in the semiconductor part of the nanohybrid catalyst underwent rapid charge separation where the electron transferred to the metal part on a sub20 fs time scale [21]. Yu et al. utilized ultrafast spectroscopy to measure carrier dynamics in $\mathrm{CdSe}$ nanorods decorated with either Au or Pt metallic tips. Both hot and cold electrons transferring from the CdSe to the metal counterpart influence the rates of charge separation, which correlates with the photocatalytic $\mathrm{H}_{2}$ evolution rate [23]

Figure 5 shows the dynamics of photoexcited carriers for $\mathrm{CdSe}, \mathrm{Pt}-\mathrm{CdSe}$, and $\mathrm{Pt}-\mathrm{CdSe}-\mathrm{Pt}$ nanostructures using two-color pump-probe optical experiments [24]. In the pump-probe experiments, femtosecond pump pulses with a wavelength of $400 \mathrm{~nm}$, obtained by frequency doubling fundamental pulses from a Ti:sapphire oscillator, are first used to excite the nanostructures; the probe pulses with energies near the band gap of the CdSe nanorods $(625 \mathrm{~nm}$ for $\mathrm{CdSe}, 615 \mathrm{~nm}$ for $\mathrm{Pt}-\mathrm{CdSe}$ and $\mathrm{Pt}-\mathrm{CdSe}-\mathrm{Pt}$ ) were generated by doubling near-infrared femtosecond pulses from an optical parametric oscillator. The relative optical transmission change $(\Delta T / T)$ of the probe pulse were measured as a function of time delay between the pump and probe pulses to monitor the carrier population at the band edge states of the CdSe nanorods, as shown in Fig. 5a, b. The temporal resolution, which was determined by the duration of the probe pulses, was around $250 \mathrm{fs}$. Nanostructures dispersed onto quartz substrates were measured with a pump intensity of $4 \mu \mathrm{J} / \mathrm{cm}^{2}$ at the laser spot.

Figure $5 \mathrm{c}$ shows the time-resolved transmission change of the probe beam after photoexcitation by pump pulses at 


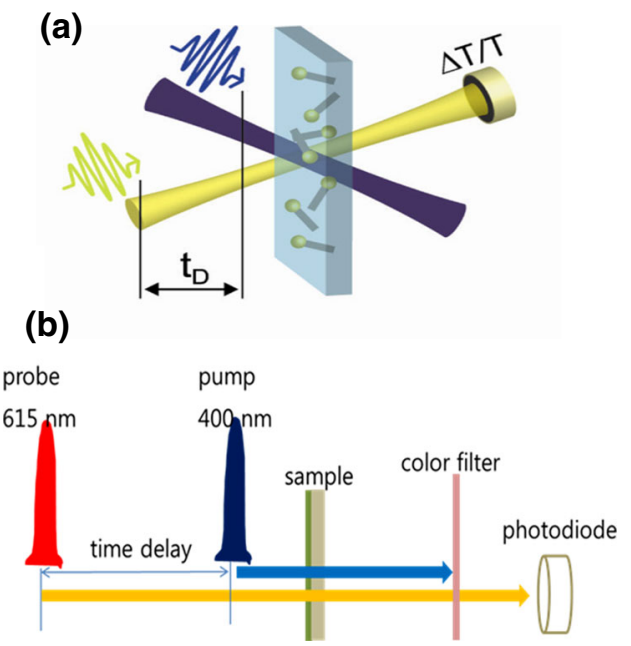

(c)

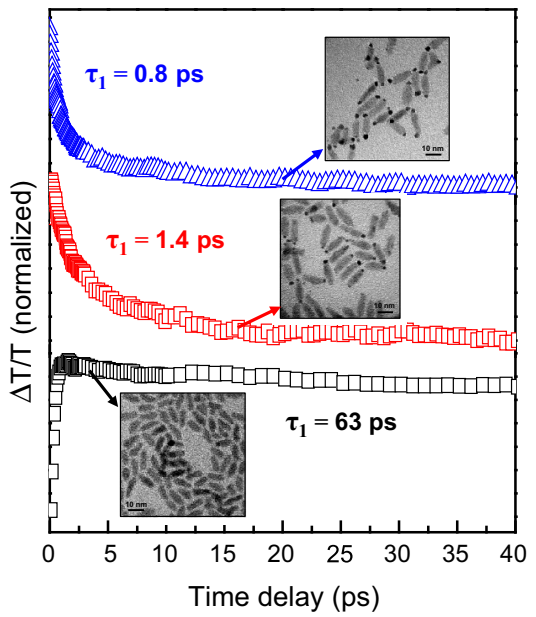

(black square CdSe nanorod, red square $\mathrm{Pt}-\mathrm{CdSe}$ nanorod, and blue triangle $\mathrm{Pt}-\mathrm{CdSe}-\mathrm{Pt}$ nanodumbbell). The bi-exponential fitting parameters of decay times and amplitudes are denoted for each data set. Reprinted from Ref. [21, 24]. Copyright 2014, with permission from the American Chemical Society

irradiated on the $\mathrm{Au} / \mathrm{TiO}_{2}$ nanoparticle system, electrons transfer from the plasmon band of the gold nanodots to the conduction band of the $\mathrm{TiO}_{2}$ nanoparticle within 240 femtoseconds (the time resolution of the apparatus was obtained using a silicon plate), as shown in Fig. 6a. Here, the femtosecond IR-probe is used to identify the injected electrons in the $\mathrm{TiO}_{2}$ conduction band from the gold nanodots, which are known to show strong intraband absorption in the IR region [30].

Figure $6 \mathrm{~b}$ shows the transient absorption kinetics for $\mathrm{Au} / \mathrm{TiO}_{2}$ and $\mathrm{N} 3 / \mathrm{TiO}_{2}$ ( $\mathrm{N} 3$ is a ruthenium complex dye) after correction for laser power as well as the corresponding absorption fraction for each sample. A remarkable point in Fig. $6 \mathrm{~b}$ is the transient absorption signal of $\mathrm{Au} / \mathrm{TiO}_{2}$ that shows significant evidence of electrons being injected into the $\mathrm{TiO}_{2}$ from the gold nanodot, while the $\mathrm{Au} /$ $\mathrm{ZrO}_{2}$ doesn't show any transient absorption, meaning no electron transfer from the gold nanodots to the $\mathrm{ZrO}_{2}$ at the probe wavelength $(3,500 \mathrm{~nm})$. Electrons injected into the $\mathrm{TiO}_{2}$ nanoparticle are observed to decay through back electron transfer to the gold nanodots for times up to $1 \mathrm{~ns}$. This back electron transfer process is dependent on the $\mathrm{TiO}_{2}$ particle diameter, showing that it is slower when the $\mathrm{TiO}_{2}$ particle size increases because the diffusion distances of free electrons within $\mathrm{TiO}_{2}$ are farther before the electrons come back to the $\mathrm{Au}$ nanodot $[27,28] . \mathrm{N} 3 / \mathrm{TiO}_{2}$ is a reference used to compare the electron injection yield because it is known to give an efficient charge separation yield of $\sim 100 \%$, whereas the yield of $\mathrm{Au} / \mathrm{TiO}_{2}$ is estimated to be about $40 \%$, compared with $\mathrm{N} 3 / \mathrm{TiO}_{2}$. 
(a)

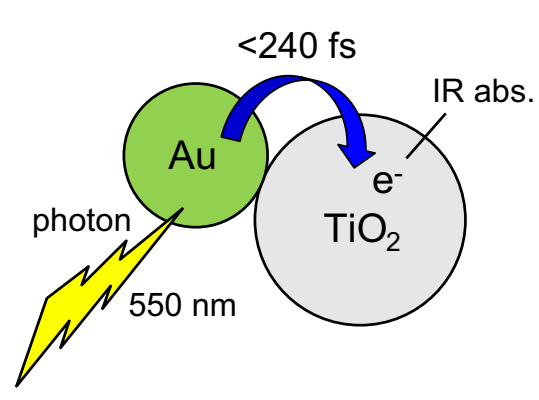

Fig. 6 a Schematic diagram of a gold nanodot attaching to a $\mathrm{TiO}_{2}$ nanoparticle, also indicating the revealed electron injection process. b Transient absorption kinetics at 3,500 $\mathrm{nm}$ for nanocrystalline films (green $\mathrm{N} 3 / \mathrm{TiO}_{2}$, red $\mathrm{Au} / \mathrm{TiO}_{2}$, gray $\mathrm{Au} / \mathrm{ZrO}_{2}$ ). The blue line shows

\section{Detection of Chemically Induced Hot Electrons Using Solid-State Devices}

Over the last several decades, many scientists have made greater efforts to respond to the question regarding the role of hot electrons on surface chemical reactions, both theoretically and experimentally. As direct experimental evidence for electron-mediated energy transfer during chemical reactions, chemiluminescence and exoelectron emission have been reported in many studies since the 1970s [31-37]. In the dissociative chemisorption of halogen molecules on alkali metals, two electrons are typically transferred via two steps: the first electron is from the metal into the molecular affinity level accelerating dissociation, and the second electron can be either the emission of the excited electron into the vacuum (exoelectron emission) or the relaxation energy $(h v)$ via photon generation (chemiluminescence) because of the unoccupied atomic affinity level on the metal surface. For detection of chemically induced exoelectrons or photons on the metal surface, the kinetic energy of the electron must have an energy greater than the work function of the metal, which is limited to the case of adsorption of a very electronegative atom or molecule onto a metal with a low work function in the range of 2-3 eV [38]. Therefore, it was hardly possible to observe the generation of hot electrons in common surface chemical reactions with lower exothermicity.

To observe the chemically induced electron excitations at transition metal surfaces constituting general heterogeneous catalysis, metal-semiconductor Schottky diodes $(\mathrm{Ag} / \mathrm{n}-\mathrm{Si}$ and $\mathrm{Cu} / \mathrm{n}-\mathrm{Si})$ were suggested as a unique hot carrier detector by Nienhaus et al. in 1999 [39-41]. When the $\mathrm{Ag}$ or $\mathrm{Cu}$ film surfaces were exposed to thermal hydrogen or deuterium atoms, charge carriers excited at the surface were detected as chemicurrent in the diode. Figure $7 \mathrm{a}$ shows a schematic of the structure of the (b)

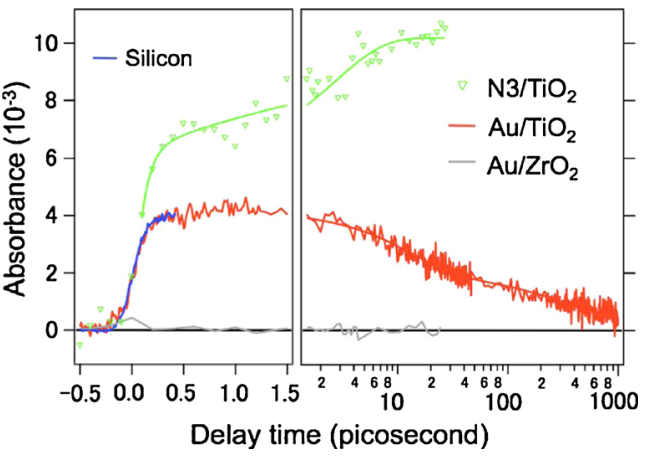

the response of the apparatus, obtained using a silicon plate. Reprinted from Ref. [29]. Copyright 2014, with permission from the American Chemical Society

Schottky diode and the principle of current production. The thickness of the metal film on which the reaction occurs was determined considering the short elastic mean free path of electrons in metals (i.e., typically $10 \mathrm{~nm}$ ). Excited electrons with sufficient energy $(1-3 \mathrm{eV})$ can reach the metal-semiconductor interface ballistically without significant attenuation and move across the Schottky barrier, which is much lower than the metal work function, resulting in production of hot electron flows. The Schottky barrier height can be adjusted by changing the metal and interface properties. Furthermore, the direct detection of a hot hole injected from the metal film is also possible with a p-type Schottky diode and cannot be observed in emission experiments. Due to the several advantages of the devices, chemicurrent measurements have been carried out in various chemisorption reactions (e.g., $\mathrm{H}, \mathrm{O}, \mathrm{Xe}, \mathrm{NO}, \mathrm{NO}_{2}$, $\mathrm{C}_{2} \mathrm{H}_{4}, \mathrm{C}_{6} \mathrm{H}_{6}$ ) on different metal surfaces in a series of studies [42], and confirmed that energy dissipation of the exothermic reaction on the metal surface is not effectively mediated by phonon excitation, but rather by electronic excitation.

Alternatively, tunnel devices, such as metal-insulatormetal (MIM) and metal-oxide-semiconductor (MOS), can also be used to detect electronic excitations created by exothermic reactions at the metal surface, as illustrated in Fig. 7b, c [38, 43, 44]. Since the tunneling mechanism allows excited electrons with somewhat lower energy to pass through the insulator layer, the transient chemicurrent was successfully measured when atomic and molecular gases (e.g., $\mathrm{H}, \mathrm{D}, \mathrm{O}, \mathrm{C}_{2} \mathrm{H}_{4}$ ) were impinged on the Au top layer of $\mathrm{Au} / \mathrm{TaO}_{\mathrm{x}} / \mathrm{Ta}(\mathrm{MIM})$ [45] and $\mathrm{Au} / \mathrm{Al}_{2} \mathrm{O}_{3} / \mathrm{n}-\mathrm{Si}$ (MOS) [43] tunnel junctions. Additionally, these tunnel devices allow for variation of the barrier by an external voltage due to displacement of the Fermi levels of the two materials with respect to each other, whereas Schottky diodes have a fixed barrier that cannot be adjusted by 
(a)

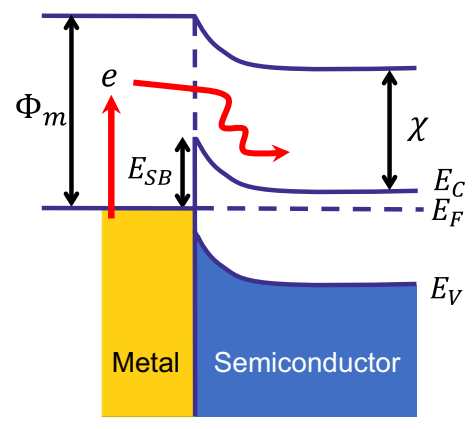

(b)

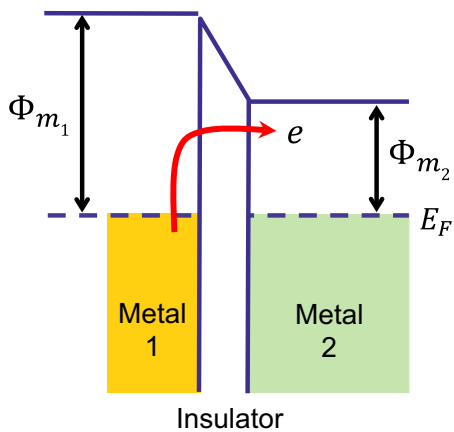

(c)

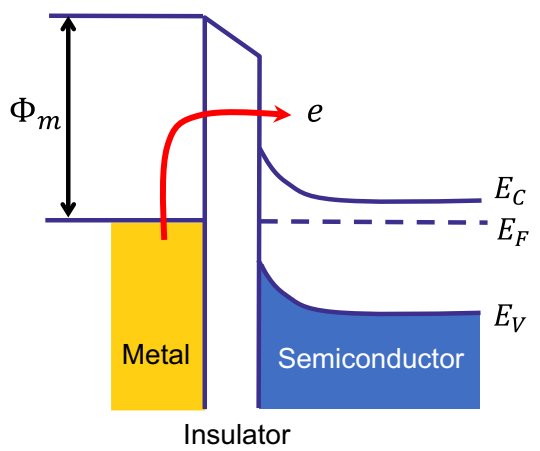

Fig. 7 Principle of chemicurrent detection with a an $n$-type Schottky diode, b a MIM tunnel device, and $\mathbf{c}$ a MOS device. Hot charge carriers excited during chemical reaction move ballistically from the metal surface to the interface. The top metal film thickness is typically in the $10 \mathrm{~nm}$ range. Reprinted from Ref. [43]. Copyright 2014, with permission from Elsevier

\section{(a)}

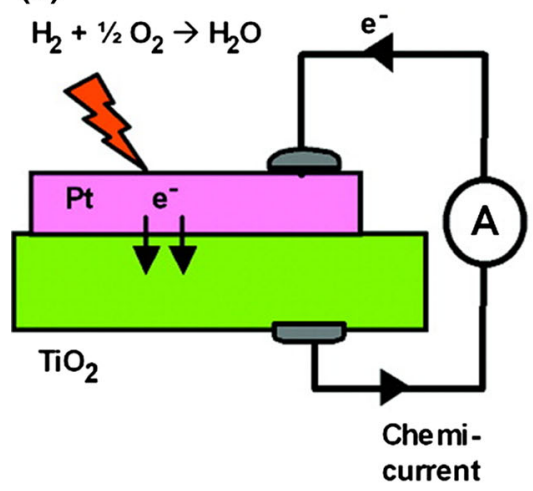

Fig. 8 a Schematic of hot electron generation on a $\mathrm{Pt} / \mathrm{TiO}_{2}$ Schottky diode during $\mathrm{H}_{2}$ oxidation. The catalytic $\mathrm{Pt}$ film is very thin $(\sim 5 \mathrm{~nm})$ to detect hot electron flows. b Arrhenius plots obtained from chemicurrent and turnover measurements on a $\mathrm{Pt} / \mathrm{TiO}_{2}$ diode with pressure of 6 Torr $\mathrm{H}_{2}$ and 760 Torr $\mathrm{O}_{2}$. The similar activation

applying an external electrical potential. If monitoring the dynamics of hot electrons under variable bias becomes feasible, it is expected to be utilized in spectroscopic study of hot electrons, which will provide profound insights into the distribution of energy during surface catalytic reactions.

\section{Correlation Between Hot Electrons and Catalytic Activity in Metal-Oxide Nanostructures}

Even though many experimental results have indicated that the metal-oxide interface plays a key role in determining catalytic activity, the origin of the strong metal-support interaction (SMSI) has not been clarified due to the lack of proper experimental measurement techniques [13, 46, 47]. The origin of enhanced catalytic activity at the metalsemiconductor interface has usually been attributed to

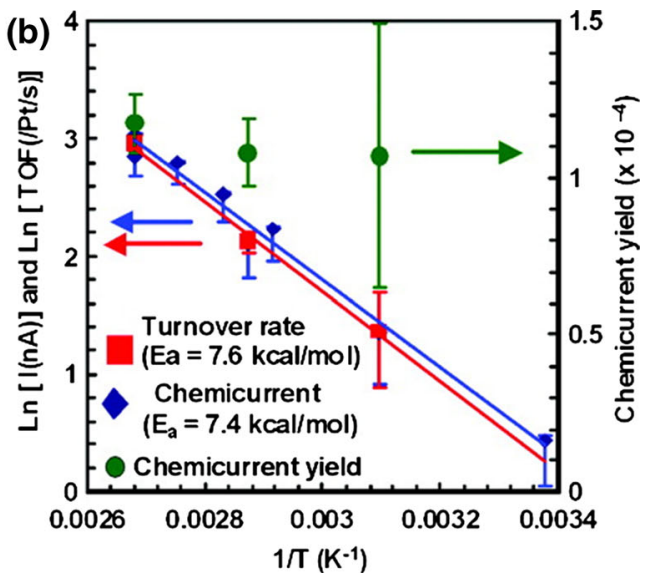

energies indicate that hot electron generation under hydrogen oxidation is proportional to the catalytic turnover rate. Reprinted from Ref. [55]. Copyright 2014, with permission from the American Chemical Society

either a geometric effect (i.e., charged metal surface at the interface) or electronic effect (i.e., charge transfer between the metal and the semiconductor) [13, 48]. Therefore, catalytic nanodiodes that are composed of a thin metal catalyst and an oxide have received great attention as an appropriate measurement technique to conclude the argument because it can simultaneously detect charge transfer through the metal-semiconductor interfaces while also taking turnover rate measurements.

Early experiments utilizing a metal-semiconductor Schottky diode to elucidate fundamental insights into the dynamics of chemical processes at metal surfaces were conducted at low-temperature and ultrahigh vacuum conditions [41]. Since 2005, however, Somorjai's group has extended this approach to high-temperature and -pressure systems that are identical to practical catalysis conditions $[49,50]$. As a model system, oxidation of carbon monoxide 
Table 1 Summary of activation energies on each type of diode in various chemical reactions

\begin{tabular}{|c|c|c|c|c|c|}
\hline \multirow[t]{2}{*}{ Type of diode } & \multirow[t]{2}{*}{ Reaction system } & \multirow[t]{2}{*}{ Partial pressure (Torr) } & \multicolumn{2}{|c|}{ Activation energy $(\mathrm{kcal} / \mathrm{mol})$} & \multirow[t]{2}{*}{ References } \\
\hline & & & Chemicurrent & Turnover rate & \\
\hline $\mathrm{Pt} / \mathrm{TiO}_{2}$ & CO oxidation & $\mathrm{CO}(40) / \mathrm{O}_{2}(100)$ & $21.3 \pm 0.7$ & $22.4 \pm 1.3$ & {$[49,50]$} \\
\hline $\mathrm{Pt} / \mathrm{GaN}$ & CO oxidation & $\mathrm{CO}(40) / \mathrm{O}_{2}(100)$ & $20.6 \pm 1.1$ & $21.3 \pm 1.3$ & {$[50]$} \\
\hline $\mathrm{Pd} / \mathrm{TiO}_{2}$ & $\mathrm{CO}$ oxidation & $\mathrm{CO}(40) / \mathrm{O}_{2}(100)$ & $20.4 \pm 1.1$ & $21.1 \pm 0.9$ & {$[50]$} \\
\hline $\mathrm{Pt} / \mathrm{TiO}_{2}$ & $\mathrm{H}_{2}$ oxidation & $\mathrm{H}_{2}(6) / \mathrm{O}_{2}(760)$ & $7.4 \pm 0.3$ & $7.6 \pm 0.6$ & {$[52]$} \\
\hline $\mathrm{Rh} / \mathrm{TiO}_{\mathrm{x}}$ & $\mathrm{CO} / \mathrm{NO}$ reaction & $\mathrm{CO}(8) / \mathrm{NO}(8)$ & 25.4 & 26.1 & [53] \\
\hline $\mathrm{Rh} / \mathrm{GaN}$ & $\mathrm{CO} / \mathrm{NO}$ reaction & $\mathrm{CO}(8) / \mathrm{NO}(8)$ & 31.7 & 32.8 & {$[53]$} \\
\hline
\end{tabular}

Fig. 9 a TEM image and scheme of a $\mathrm{Pt} / \mathrm{SiO}_{2} / \mathrm{TiO}_{2}$ hybrid nanocatalyst [59]. b TEM images of $\mathrm{Pt}$ nanoparticles deposited with arc plasma deposition on a $\mathrm{TiO}_{2}$ substrate [60]. c Scheme of AFM experiments on Au islands on a $\mathrm{TiO}_{2}$ substrate (left) and conductance mapping (right) [61]. Reprinted from Ref. [43, 59-61]. Copyright 2014, with permission from the Royal Society of Chemistry [59], the American Chemical Society [60], and the American Institute of Physics [61] (a)

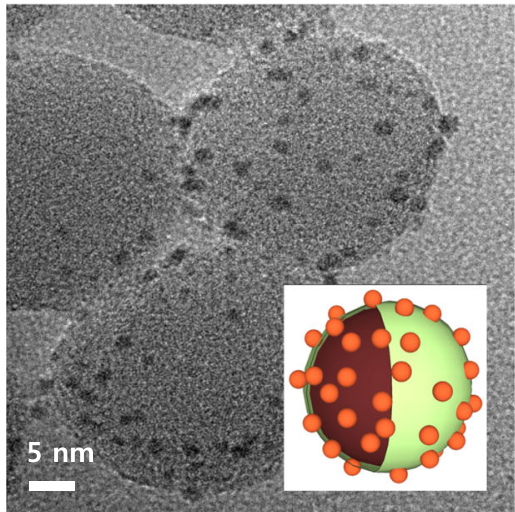

(b)

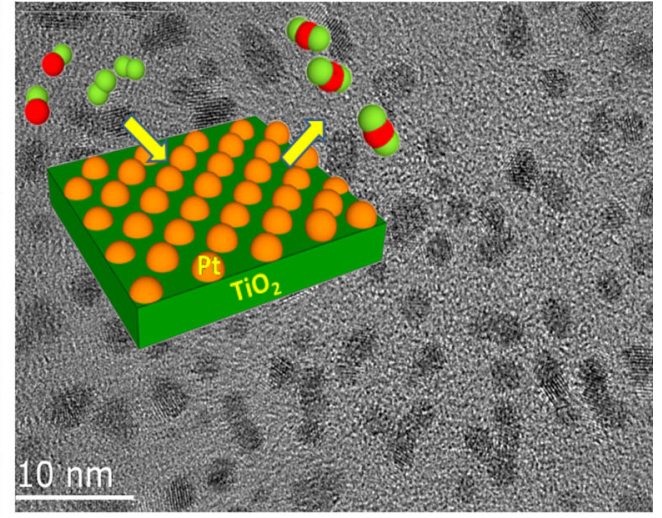

(c)

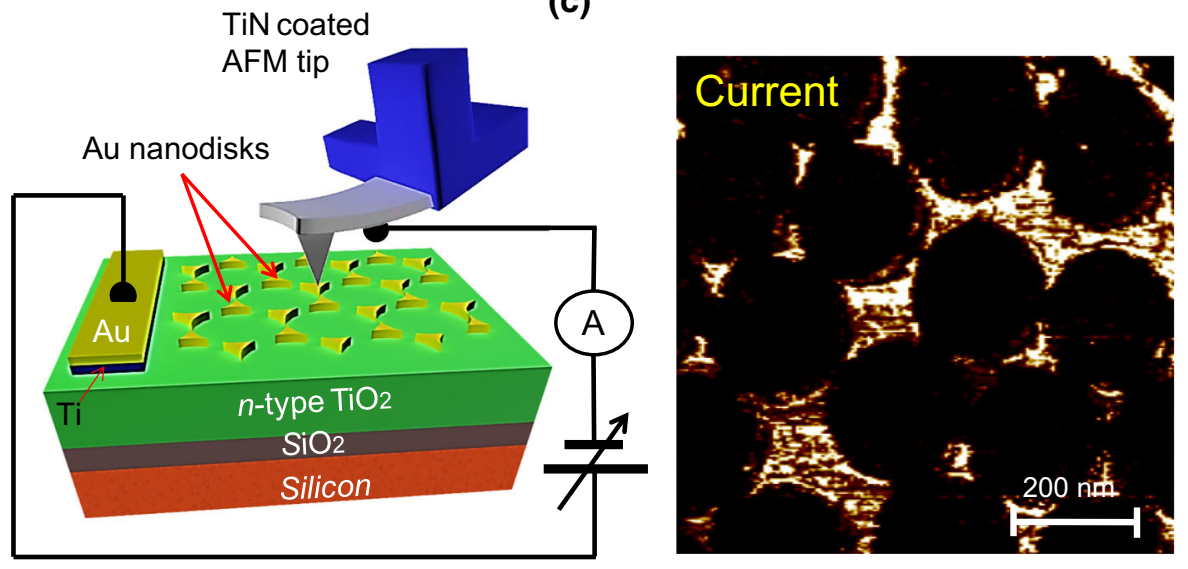

on platinum was chosen where a total energy of $2.9 \mathrm{eV}$ is released via several elementary reaction steps, including chemisorption of $\mathrm{CO}$ and $\mathrm{O}_{2}$ molecules, dissociation to two $\mathrm{O}$ atoms, and formation of $\mathrm{CO}_{2}$. They fabricated two types of catalytic nanodiode, $\mathrm{Pt} / \mathrm{TiO}_{2}$ and $\mathrm{Pt} / \mathrm{GaN}$, and carried out catalytic oxidation of $\mathrm{CO}$ under 100 Torr $\mathrm{O}_{2}$ and 40 Torr CO at temperatures between 353 and $473 \mathrm{~K}$ [51]. Since hot electrons generated on the Pt surface during exothermic reactions have enough kinetic energy to overcome the Schottky barrier $(1.2 \mathrm{eV})$, a steady-state current was observed, implying that the reaction occurred and that the product rapidly left the surface; whereas a transient current was generated from the chemisorption reaction because of the eventual surface saturation. This confirmed that the generation of hot electrons is proportional to the rate of $\mathrm{CO}$ oxidation on the $\mathrm{Pt}$ surface by comparing the chemicurrent with the accumulation of $\mathrm{CO}_{2}$.

Later, Park et al. clearly verified a quantitative correlation between hot electrons and catalytic activity, showing that the activation energies of chemicurrent and turnover rate are very similar during exothermic reactions [52-55]. In every experiment, the effective chemicurrent was 
obtained by excluding an additional electric current caused by a temperature gradient across the nanodiode, which is called the thermoelectric current. The activation energies were determined using the slope of the Arrhenius plot of chemicurrent or turnover rate as a function of temperature under exothermic reactions.

Figure $8 \mathrm{a}, \mathrm{b}$ shows a scheme of the detection of ballistic hot electrons in the $\mathrm{Pt} / \mathrm{TiO}_{2}$ catalytic nanodiode and Arrhenius plots of both chemicurrent and turnover rate measurements under $\mathrm{H}_{2}$ oxidation condition, respectively. The activation energy of hydrogen oxidation obtained from the chemicurrent through the $\mathrm{Pt} / \mathrm{TiO}_{2}$ nanodiode is $7.4 \pm 0.3 \mathrm{kcal} / \mathrm{mol}$, which is well-matched with that from the turnover rate $(7.6 \pm 0.6 \mathrm{kcal} / \mathrm{mol})$ [55]. The similar activation energies imply that the chemicurrent originates from the catalytic reaction and that catalytic nanodiodes can replace turnover rate measurements (e.g., gas chromatography and mass spectroscopy). This phenomenon was not only confirmed by using other metal thin films, but also via various catalytic reactions $[53,55,56]$. Table 1 gives a summary of the activation energies obtained from chemicurrent and turnover rate, which were investigated under various reaction systems. Investigation of catalyzed reactions by catalytic nanodiodes, therefore, provides valuable insight into the role of electron excitation and flow in chemical reactivity of oxide-supported metal catalytic systems for various reactions.

\section{Perspective and Concluding Remarks}

The future direction of metal-oxide interface and hot electron research includes several topics, such as development of new model catalysts systems and surface characterization of metal-oxide interfaces, as shown in Fig. 9. Combined with the advancement of colloid chemistry and nanotechnology, new catalysts (e.g., nanoparticles with controlled size, shape, and composition; and multifunctional nanocatalysts, such as core-shell and yolk-shell) have been developed [57, 58]. Figure 9a shows hybrid metal-oxide nanocatalysts that can be model systems for investigating metal-oxide interfaces. Here, metal nanoparticles were deposited on functionalized $\mathrm{SiO}_{2}$ and an ultrathin layer of $\mathrm{TiO}_{2}$ was then selectively coated on the $\mathrm{SiO}_{2}$ surface to prevent sintering and to provide high thermal stability, while maximizing the metal-oxide interface for higher catalytic activity [59]. The types of oxides and metal nanoparticles can be changed, thus allowing the catalytic properties of various combinations of metals and oxides to be tested within this framework.

Two-dimensional model catalysts are important because they can be well characterized using various surface techniques. Figure 9b shows two-dimensional arrays of metal nanoparticles, fabricated via arc plasma deposition that can be useful model systems to study the effect of the metaloxide interface [60]. The nanoscale charge transport properties of metal-oxide systems can be studied by means of various surface techniques. For example, Lee et al. utilized conductive probe atomic force microscopy on $\mathrm{Au}$ nanoislands on $\mathrm{TiO}_{2}$ to investigate the charge flows and the change in Schottky barrier height of nanosized islands, as shown in Fig. 9c [61]. Here, Au nanoislands were fabricated in selfassembled patterns on an n-type $\mathrm{TiO}_{2}$ semiconductor film using the Langmuir-Blodgett process for the silica particles. Investigation of the physical, electronic, and chemical properties of metal-oxide interfaces and their influences on catalytic activity and selectivity is a key issue for "bridging the materials gap" and will be an active research area in heterogeneous catalysis.

In conclusion, we highlighted recent studies of the role of hot electron flows in surface chemistry and heterogeneous catalysis. We discussed the SMSI effects on various catalytic systems to address the role of the metal-oxide interface to determine the catalytic activity and selectivity of heterogeneous catalysis. Generation and detection of hot electron flows with several different schemes were shown. The strong correlation between hot electron generation and the turnover rates of catalyzed reactions were shown for several catalysts and reactions. We showed the spectroscopic study of fast charge transfer occurring at the interface between the metal and oxides with femtosecond time resolution. The developing research on new model catalysts with well-defined metal-oxide interfaces and microscopic techniques to probe nanoscale charge transport through metal-oxide interfaces was introduced.

Acknowledgments The work was supported by IBS-R004-G4.

\section{References}

1. Freund HJ, Kuhlenbeck H, Libuda J, Rupprechter G, Baumer M, Hamann H (2001) Top Catal 15:201

2. Somorjai GA, Park JY (2008) J Chem Phys 128:182504

3. Somorjai GA, York RL, Butcher D, Park JY (2007) Phys Chem Chem Phys 9:3500

4. Haruta M, Yamada N, Kobayashi T, Iijima S (1989) J Catal 115:301

5. Fujitani T, Nakamura I (2011) Angew Chem Int Edit 50:10144

6. Boffa A, Lin C, Bell AT, Somorjai GA (1994) J Catal 149:149

7. Park D, Kim SM, Kim SH, Yun JY, Park JY (2014) Appl Catal 480:25

8. Baker LR, Hervier A, Seo H, Kennedy G, Komvopoulos K, Somorjai GA (2011) J Phys Chem C 115:16006

9. Goddeti KC, Kim SM, Lee YK, Kim SH, Park JY (2014) Catal Lett 144:1411

10. Schwab GM, Koller K (1968) J Am Chem Soc 90:3078

11. Schwab GM (1969) Surf Sci 13:198

12. Solymosi F (1968) Catal Rev: Sci Eng 1:233 
13. Hayek K, Fuchs M, Klotzer B, Reichl W, Rupprechter G (2000) Top Catal 13:55

14. Hu P, Huang Z, Amghouz Z, Makkee M, Xu F, Kapteijin F, Dikhtiarenko A, Chen Y, Gu X, Tang X (2014) Angew Chem Int Edit 53:3418

15. Tauster SJ, Fung SC, Baker RTK, Horsley JA (1981) Science 211:1121

16. Willinger MG, Zhang W, Bondarchuk O, Shaikhutdinov S, Freund HJ, Schlogl R (2014) Angew Chem Int Edit 53:5998

17. Schwab GM (1982) Crc Cr Rev Sol State 10:331

18. Kennedy G, Baker LR, Somorjai GA (2014) Angew Chem Int Edit 53:3405

19. Jailaubekov AE, Willard AP, Tritsch JR (2013) Nat Mater 12: 66 $\mathrm{AE}$

20. Lei C, Bauer M, Read K, Tobey R, Liu Y, Popmintchev T, Murnane MM, Kapteyn HC (2002) Phys Rev B 66:245420

21. Mongin D, Shaviv E, Maioli P, Crut A, Banin U, Del Fatti N, Vallee F (2012) ACS Nano 6:7034

22. Tvrdy K, Frantsuzov PA, Kamat PV (2011) Proc Natl Acad Sci USA 108:29

23. Yu P, Wen XM, Lee YC, Lee WC, Kang CC, Tang J (2013) J Phys Chem Lett 4:3596

24. Kim SM, Lee SJ, Kim SH, Kwon S, Yee KJ, Song H, Somorjai GA, Park JY (2013) Nano Lett 13:1352

25. Klimov VI, McBranch DW, Leatherdale CA, Bawendi MG (1999) Phys Rev B 60:13740

26. Du L, Furube A, Hara K, Katoh R, Tachiya M (2009) Thin Solid Films 518:861

27. Du LC, Furube A, Hara K, Katoh R, Tachiya M (2013) J Photochem Photobiol C 15:21

28. Du LC, Furube A, Yamamoto K, Hara K, Katoh R, Tachiya M (2009) J Phys Chem C 113:6454

29. Furube A, Du L, Hara K, Katoh R, Tachiya M (2007) J Am Chem Soc 129:1485

30. Asbury JB, Hao E, Wang YQ, Ghosh HN, Lian TQ (2001) J Phys Chem B 105:4545

31. Greber T (1997) Surf Sci Rep 28:1

32. Hellberg L, Strömquist J, Kasemo B, Lundqvist BI (1995) Phys Rev Lett 74:4742

33. Kasemo B, Törnqvist E, Nørskov J, Lundqvist B (1979) Surf Sci 89:554

34. Kasemo B, Törnqvist E, Wallden L (1980) Mater Sci Eng 42:23

35. Kasemo B, Wallden L (1975) Surf Sci 53:393

36. Newns D, Makoshi K, Brako R, vaN WuNNik JNM (1983) Phys Scrip 1983:5
37. Ramsier R, Yates J Jr (1991) Surf Sci Rep 12:246

38. Nienhaus H, Gergen B, Weinberg W, McFarland E (2002) Surf Sci 514:172

39. Nienhaus H, Bergh H, Gergen B, Majumdar A, Weinberg W, McFarland E (1999) Phys Rev Lett 82:446

40. Nienhaus H, Bergh HS, Gergen B, Majumdar A, Weinberg WH, McFarland EW (1999) Appl Phys Lett 74:4046

41. Nienhaus H (2002) Surf Sci Rep 45:1

42. Gergen B, Nienhaus H, Weinberg WH, McFarland EW (2001) Science 294:2521

43. Liu X, Cuenya BR, McFarland E (2004) Sensors and Actuators B 99:556

44. Cuenya BR, Nienhaus H, McFarland EW (2004) Phys Rev B 70:115322

45. Mildner B, Hasselbrink E, Diesing D (2006) Chem Phys Lett 432:133

46. Penner S, Wang D, Podloucky R, Schlögl R, Hayek K (2004) Phys Chem Chem Phys 6:5244

47. Rupprechter G, Seeber G, Goller H, Hayek K (1999) J Catal 186:201

48. Haller GL, Resasco DE (1989) Adv Catal 36:173

49. Somorjai GA (2005) Catal Lett 101:1

50. Park JY, Renzas J, Contreras A, Somorjai GA (2007) Top Catal 46:217

51. Ji X, Zuppero A, Gidwani JM, Somorjai GA (2005) J Am Chem Soc 127:5792

52. Park JY, Somorjai GA (2006) ChemPhysChem 7:1409

53. Park JY, Renzas J, Hsu BB, Somorjai GA (2007) J Phys Chem C 111:15331

54. Park JY, Somorjai GA (2006) J Vac Sci Technol B 24:1967

55. Hervier A, Renzas JR, Park JY, Somorjai GA (2009) Nano Lett 9:3930

56. Renzas JR, Somorjai GA (2010) J Phys Chem C 114:17660

57. Joo SH, Park JY, Tsung CK, Yamada Y, Yang PD, Somorjai GA (2009) Nat Mater 8:126

58. Somorjai GA, Park JY (2008) Top Catal 49:126

59. Reddy AS, Kim S, Jeong HY, Jin S, Qadir K, Jung K, Jung CH, Yun JY, Cheon JY, Yang JM, Joo SH, Terasaki O, Park JY (2011) Chem Commun 47:8412

60. Qadir K, Kim SH, Kim SM, Ha H, Park JY (2012) J Phys Chem C 116:24054

61. Lee H, Lee YK, Van TN, Park JY (2013) Appl Phys Lett 103:173103 